\title{
Comparative Meiotic Studies in Triatoma sordida (Stål) and T. guasayana Wygodzinsky \& Abalos (Reduviidae, Heteroptera)
}

\author{
P Rebagliati, AG Papeschi, LM Mola, S Pietrokovsky*, P Gajate*, V Bottazzi*, \\ C Wisnivesky-Colli*/+
}

Laboratorio de Genética *Unidad de Ecología de Reservorios y Vectores de Parásitos, Departamento de Ciencias Biológicas, Facultad de Ciencias Exactas y Naturales, UBA, Ciudad Universitaria, Pab. II, 1428,

Buenos Aires, Argentina

Triatoma sordida and $\mathrm{T}$. guasayana are competent Trypanosoma cruzi vectors, with overlapping distribution areas in Argentina. Both species are morphologically similar, and their immature stages are hard to discriminate. Cytogenetic studies in the genus Triatoma reveal scarce karyotypic variations, being $2 n=20+X Y$ the most frequent diploid number in males.

In the present work the meiotic behaviour of different Argentinian populations of $\mathrm{T}$. sordida and $\mathrm{T}$. guasayana has been analyzed; the meiotic karyotype of both species has also been compared. The species differ in total chromosome area and in the relative area of the sex chromosomes. These meiotic karyotypic differences constitute an additional tool for the taxonomic characterization of $\mathrm{T}$. sordida and T. guasayana. The analysis of an interpopulation hybrid of $\mathrm{T}$. sordida (Brazil x Argentina) reveals a regular meiotic behaviour, despite the presence of heteromorphic bivalents. Our observations support the hypothesis that karyotype variations through the gain or loss of heterochromatin can not be considered as a primary mechanism of reproductive isolation in Triatoma.

Key words: Triatoma - holokinetic chromosomes - Heteroptera - meiotic karyotype - meiotic behaviour

Triatoma sordida (Stål) and T. guasayana Wygodzinsky \& Abalos are competent Trypanosoma cruzi vectors, with overlapping distribution areas. T. sordida is widely distributed from the Cerrado region of Brazil to the Chaco region in Argentina and T. guasayana is found in central and northern Argentina, Bolivia and Paraguay (Forattini 1980, Wisnivesky-Colli et al. 1993). Both species have been found in the Chaco region, Departamento de Santa Cruz (Bolivia), and in the northern and central provinces in Argentina; $T$. sordida predominates in the eastern part of the humid Chaco region, while T. guasayana is more abundant in its drier western part (Wisnivesky-Colli et al. 1997). Both species are mainly sylvatic, but may colonize peridomestic and domestic environments. T. sordida and T. guasayana are morphologically similar, and their immature stages are hard

\footnotetext{
This work was supported by grants to Dr L Poggio and Dr L Mola (Ex 127) and to Dr C Wisnivesky (Ex 184) from the Secretaría de Ciencia y Técnica de la Universidad de Buenos Aires.

${ }^{+}$Corresponding author. Fax: +54-1-782.0582. E-mail: criswi@biolo.bg.fcen.uba.ar

Received 7 August 1997

Accepted 2 March 1998
}

to discriminate; this has led to difficulties in their taxonomic identification (Abalos \& Wygodzinsky 1951, Usinger et al. 1966, Gorla et al. 1993).

In the present study the meiotic behaviour and meiotic karyotype of T. sordida and T. guasayana from different localities of Argentina are compared, in order to contribute to the taxonomic characterization of both species. Within the genus Triatoma, 31 species of the 70 described have been so far cytogenetically analyzed (Panzera et al. 1996). The most frequent autosomal number is 20 , the only exceptions being $T$. rubrofasciata $\left(2 \mathrm{n}=22+\mathrm{X}_{1} \mathrm{X}_{2}\right.$ $\mathrm{Y})$ and T. nitida $\left(2 \mathrm{n}=18+\mathrm{X}_{1} \mathrm{X}_{2} \mathrm{Y}\right)$. The sex chromosome determining mechanisms encountered are $\mathrm{XY} / \mathrm{XX}$ (male/ female) (15 species), $\mathrm{X}_{1} \mathrm{X}_{2} \mathrm{Y} / \mathrm{X}_{1}$ $\mathrm{X}_{1} \mathrm{X}_{2} \mathrm{X}_{2}$ (12 species) and $\mathrm{X}_{1} \mathrm{X}_{2} \mathrm{X}_{3} \mathrm{Y} / \mathrm{X}_{1} \mathrm{X}_{1} \mathrm{X}_{2}$ $\mathrm{X}_{2} \mathrm{X}_{3} \mathrm{X}_{3}$ (2 species). T. sordida has been cytogenetically studied by Schreiber and Pellegrino (1950) and Barth (1956) in males from Brazil $(2 \mathrm{n}=20+$ $\mathrm{XY}$ ), while the diploid number of $T$. guasayana $(2 n=20+X Y)$ has been reported by Rebagliati et al. (1995) and Hornos et al. (1996). Considering that $T$. sordida has a wide distribution area, we included a cytogenetic study of an interpopulation hybrid Brazil x Argentina; this was done to check out possible differences among populations from the Cerrado region (dispersive center of the species) with those from southern areas. 


\section{MATERIALS AND METHODS}

This study was performed on adult males from five samples of $T$. sordida and four samples of $T$. guasayana (Table I). Four samples of the former and two of the latter came from laboratory colonies founded with individuals from natural populations of Formosa and Santiago del Estero Provinces (Argentina). The specimens were given by the National Chagas Control Agency (Córdoba). The remaining samples were from natural populations: T. sordida from Corrientes (Corrientes Province), and T. guasayana from Amamá and Trinidad (neighbouring localities, Moreno Department, Santiago del Estero Province). An interpopulation hybrid of $T$. sordida has also been cytogenetically studied. The female of the cross belonged to the 6th laboratory generation $\left(\mathrm{F}_{6}\right)$ from Patiño (Formosa Province, Argentina) and the male came from a natural population of Minas Gerais (Brazil). The male hybrid was obtained at the ECORVEP (Unidad de Ecología de Reservorios y Vectores de Parásitos), Facultad de Ciencias Exactas y Naturales, Universidad de Buenos Aires.

The specimens were anaesthetized with ether, and the testes were dissected out, fixed in 3:1 (absolute ethanol: glacial acetic acid) and kept at $4^{\circ} \mathrm{C}$. Chromosomes were visualized by iron propionic haematoxylin squash. Cells at metaphase I were photographed, and chromosome areas were measured by means of an image analyzer Kontron Mini-Mop. Total chromosome areas and sex chromosome areas were compared by means of a two level nested ANOVA, and Tukey non-planned comparisons (Sokal \& Rohlf 1981).

\section{RESULTS}

Meiotic behaviour - The diploid number of $T$. sordida and $T$. guasayana is $2 \mathrm{n}=22=20+\mathrm{XY}$ in males (Figs 1A, 2A). Both species have similar cytogenetic characteristics and meiotic behaviour.

In nuclei at spermatogonial interphase of $T$. sordida few chromocenters are observed. At spermatogonial prometaphases and metaphases the holokinetic nature of the chromosomes is apparent (Fig. 1A). From the onset of meiosis up to early diakinesis, sex chromosomes are positively heteropycnotic, and are associated to the nucleolus (Fig. 1B). At middle and late diakinesis sex chromosomes can be more separated (Fig. 1C), but at metaphase I they are both axially orientated side by side at the center of the ring of autosomal bivalents (Fig. 1D); at anaphase I they divide equationally. At metaphase II, sex chromosomes form a pseudobivalent that lies again at the center of the ring of autosomes. As is characteristic in Heteroptera, autosomal bivalents exhibit only one terminal chiasma (Fig. 1C-D). No differences in the meiotic behaviour of individuals of $T$. sordida from Formosa, Santiago del Estero and Corrientes have been observed.

Meiosis in the interpopulation hybrid (Brazil $x$ Argentina) was regular, with the formation of 10 bivalents plus the $\mathrm{X}$ and $\mathrm{Y}$ univalents. Exceptionally, a ring bivalent is detected at diakinesis (Fig. 1E). At metaphase I, up to 5 heteromorphic bivalents are readily distinguished (Fig. 1F).

The meiotic behaviour of T. guasayana (Fig. 2 ) is similar to that described in T. sordida. At leptotene-zygotene sex chromosomes are positively heteropycnotic and lie close to each other at the periphery of the nucleus (Fig. 2B). At pachytene and diffuse stage they are associated through the nucleolus, and are observed as a single chromocenter (Fig. 2C-D). At diplotene and diakinesis they continue close to one another (Fig. 2E), being isopycnotic at late diakinesis. At metaphase I they orientate axially at the center of the ring of autosomal bivalents (Fig. 2F), and at metaphase II they

TABLE I

Number and origin of individuals of Triatoma sordida and T. guasayana cytogenetically analyzed

\begin{tabular}{|c|c|c|c|}
\hline Species & Locality of collection & $\begin{array}{c}\text { Studied } \\
\text { generation }\end{array}$ & $\begin{array}{c}\text { No. of individuals } \\
\text { analyzed }\end{array}$ \\
\hline \multirow[t]{2}{*}{ T. sordida } & Patiño (Formosa) & $\mathrm{F}_{4}$ & 10 \\
\hline & & $\mathrm{F}_{6}$ & 11 \\
\hline \multirow[t]{2}{*}{ T. sordida } & Rio Hondo & $\mathrm{F}_{3}$ & 11 \\
\hline & (Sgo. del Estero) & $\mathrm{F}_{4}$ & 11 \\
\hline T. sordida & Corrientes (Corrientes) & Sylvatic (1995) & 3 \\
\hline T. sordida & Hybrid ( $0^{\star}$ Brazil x + Argentina) & $\mathrm{F}_{1}$ & 1 \\
\hline \multirow[t]{4}{*}{ T. guasayana } & Rio Hondo (Sgo. del Estero) & $\mathrm{F}_{3}$ & 9 \\
\hline & & $\mathrm{F}_{4}$ & 8 \\
\hline & Amamá and Trinidad (Sgo. del Estero) & Sylvatic (1993) & 10 \\
\hline & & Sylvatic (1994) & 12 \\
\hline
\end{tabular}


Fig. 1: spermatogenesis of Triatoma sordida. A-D - T. sordida from Formosa. A: spermatogonial prometaphase; B: diffuse stage; C: diakinesis; D: metaphase I. In B and C arrowheads point sex chromosomes. E-F - Interpopulation hybrid (Brazil x Argentina). E: diakinesis with a ring bivalent (empty arrow); F: metaphase I (arrows show heteromorphic bivalents). Bar $=10 \mathrm{~mm}$. 
Fig. 2: spermatogenesis in Triatoma guasayana. A: spermatogonial prometaphase; B: leptotene-zygotene; C-D: diffuse stage; E: diakinesis; F: metaphase I; G: metaphase II. B-E: arrowheads point sex chromosomes. H-J: meiosis with B chromosome. H: metaphase I; I: metaphase II; J: telophase II. Bar $=10 \mathrm{~mm}$.

associate in a pseudobivalent, lying at the center of the autosomal ring (Fig. 2G). The meiotic behaviour of individuals from laboratory and field samples was similar. However, in laboratory samples a supernumerary chromosome was detected. All individuals from the $\mathrm{F}_{3}$ generation presented a small $\mathrm{B}$ chromosome in variable frequency (up to $50 \%$ of the cells) (Fig. 2H-I); in each individual the percentage of cells at metaphase I and metaphase II with the B chromosome is similar, suggesting that the supernumerary chromosome divides equationally at anaphase I. At anaphase II the B chromosome segregates to one pole, and is usually observed outside the telophase nucleus (Fig. 2J). The pres- 
ence of the supernumerary chromosome can be ascertained in only one individual from the $\mathrm{F}_{4}$ generation, because the other specimens had a low number of cells at proper meiotic stages.

Meiotic karyotype - Autosomes of both species are of various sizes. The sex chromosomes $\mathrm{X}$ and $\mathrm{Y}$ are of different size and the smallest of the complement (Figs 3, 4).

The comparison of the total chromosome area at metaphase I (Table II) of the samples of $T$. sordida from Formosa and Santiago del Estero, and T. guasayana, reveals significant differences in total chromosome area $(\mathrm{P}<0.02)$; differences between the two samples of $T$. sordida are not significant $(\mathrm{T}=1.63, \mathrm{a}=0.5)$ whereas the total chromosome area of $T$. guasayana is significatively lower $(\mathrm{T}=$ 3.92 and $\mathrm{T}=5.74, \mathrm{a}=0,10)$. In these comparisons, the sample of $T$. sordida from Corrientes and the interpopulation hybrid were not included due to the low number of cells at metaphase I suitable for measurements.

The statistical analysis of relative sex chromosomes areas (Table II) of T. guasayana (6.3\%) and T. sordida $(7.8 \%)$ reveals that the differences are significant $(\mathrm{P}<0.02)$.

\section{DISCUSSION}

T. sordida has been cytogenetically described by Schreiber and Pellegrino (1950) and Barth (1956), who reported $2 \mathrm{n}=20+\mathrm{XY}$ in males from Brazil. The former described the presence of three autosomal pairs with heterochromatic blocks, although smaller than those characteristic of $T$. infestans. On the other hand, Barth (1956) pointed out the presence of three larger autosomal pairs and an XY pair of similar size. More recently, Hornos et al. (1996) observed that in a population of T. sordida from Brazil autosomes had 30-35\% of heterochromatin, while the individuals from Argentina lacked autosomal heterochromatin. In the material of $T$. sordida analyzed in the present work, chromosomes decrease gradually in size and heterochromatin has not been detected. On the other hand, and in contrast with the Brazilian sample (Barth 1956), sex chromosomes show size differences (Fig. 4).

The analysis of the interpopulation hybrid of T. sordida (Brazil x Argentina) confirms the karyotypic differences reported for both populations through the presence of heteromorphic bivalents. These differences with respect to the heterochro-

Fig. 3: meiotic karyotypes at metaphase I of Triatoma sordida and T. guasayana. A: T. sordida from Formosa; B: T. sordida from Santiago del Estero; C: interpopulation hybrid of T. sordida (Brazil x Argentina) (* = heteromorphic bivalents); D: T. guasayana. Bar $=10 \mathrm{~mm}$. 


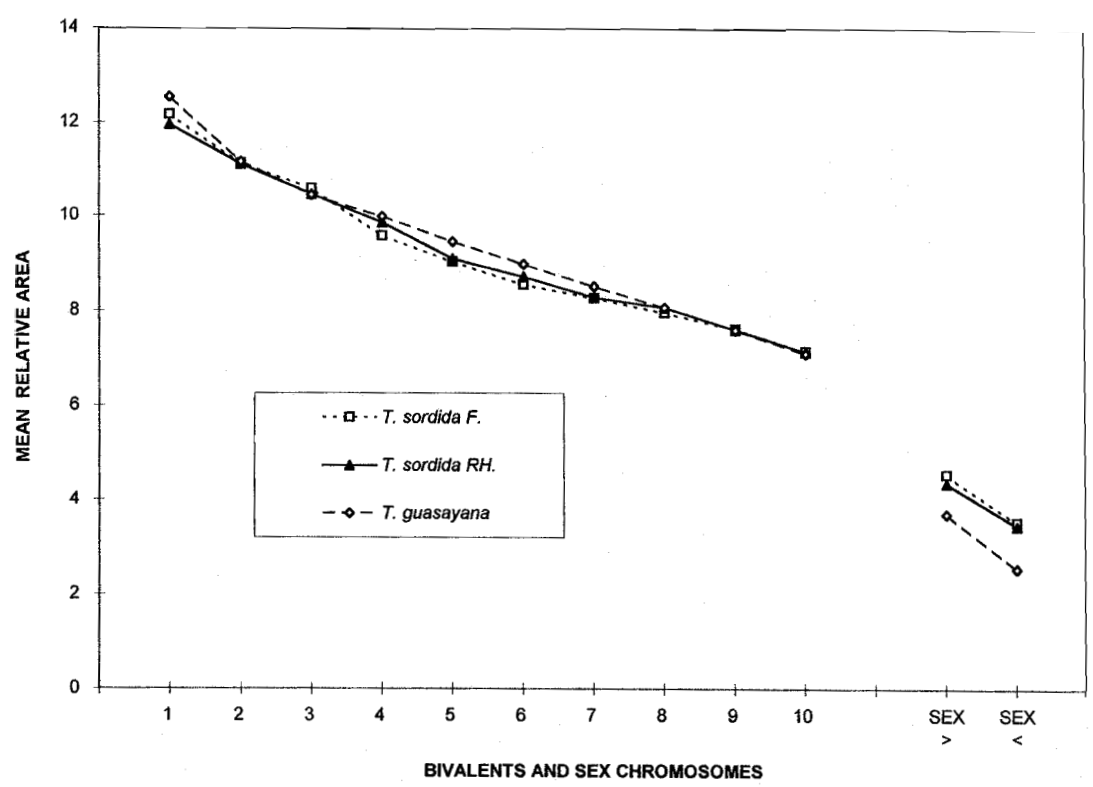

Fig. 4: mean relative chromosome area of each bivalent and of sex chromosomes at metaphase I of Triatoma sordida and T. guasayana.

\section{TABLE II}

Mean total chromosome area (in arbitrary units) and mean relative area (\%) of sex chromosomes at metaphase I of Triatoma sordida and T. guasayana

\begin{tabular}{lcccc}
\hline & $\begin{array}{c}\text { No. of } \\
\text { individuals }\end{array}$ & $\begin{array}{c}\text { Total No. } \\
\text { of cells }\end{array}$ & $\begin{array}{c}\text { Total chrom. area } \\
\bar{X} \pm \text { S.D. }\end{array}$ & $\begin{array}{c}\text { Relative sex } \\
\text { chrom. area (\%) }\end{array}$ \\
\hline $\begin{array}{l}T . \text { sordida } \\
\text { Formosa }\end{array}$ & 4 & 19 & $319.88 \pm 6.68$ (a) & 7.85 \\
$\begin{array}{l}T \text {. sordida } \\
\text { Rio Hondo }\end{array}$ & 3 & 15 & $304.73 \pm 7.36$ (a) & 6.27 \\
$T$. guasayana & 3 & 14 & $265.64 \pm 7.16$ (b) \\
\hline
\end{tabular}

(a) (b): total chromosome areas are significantly different when followed by different letters.

matin content should involve not only the three larger pairs since up to five heteromorphic bivalents have been detected. The fact that meiosis in the hybrid is regular supports the idea that differences in heterochromatin content do not necessarily affect the meiotic process (Panzera et al. 1995). In $T$. infestans, Panzera et al. (1992) pointed out that the variation in $\mathrm{C}$ positive heterochromatin content both within and between populations of the species constitute an important mechanism of karyotypic change. Since within the distribution area of $T$. sordida there are populations cytogenetically different (with and without conspicuous heterochromatic blocks), it is possible that some polymorphic populations will be encountered. It can be concluded that differentiation through gain or loss of heterochromatin can not be considered as a primary mecha- nism of reproductive isolation in Triatoma.

Preliminary cytogenetic studies of T. guasayana indicated a diploid chromosome number of $22(2 n=$ $20+$ XY, males) (Rebagliati et al. 1995, Hornos et al. 1996). In the present study, laboratory samples of this species differed from those of natural populations because the former presented a supernumerary chromosome. It can be inferred that the occurrence of a B chromosome is a consequence of inbreeding, since it is present in all 9 specimens of laboratory $\mathrm{F}_{3}$ generation and at least one from the $\mathrm{F}_{4}$ generation, and is absent in natural populations (10 and 12 individuals).

The taxonomic identification of $T$. sordida and T. guasayana has been difficult since both species are morphologically similar (Abalos \& Wygodzinsky 1951, Usinger et al. 1966). The 
multivariate analysis performed by Gorla et al. (1993) with morphometric measurements indicates that they are separate species. On the other hand, the genetic analysis of isoenzymes reveals that zymograms corresponding to hexokinases 1 and 2 (HK-1 and HK-2), mitochondrial esterase (ES-1) and soluble isocitrate-NADP dehydrogenase 2 (ICDH-2) are diagnostic loci for species identification (García et al. 1995). Our cytogenetic studies show that although there are similar traits in the meiotic process of both species, they have karyotypic differences. The relative area of sex chromosomes in T. guasayana is significatively lower than in T. sordida (20\%), and since the total chromosome area of the former is lower, the sex chromosomes of $T$. guasayana are actually smaller. The cytogenetic evidence here presented constitutes an additional tool to be used in the taxonomic characterization of these species.

\section{ACKNOWLEDGEMENTS}

To Lic. Darío Vezzari and Aníbal Carbajo for technical assistance in the field; to Lic. María Ester Bar for providing the specimens of $T$. sordida from Corrientes; to Lic. B. González for advice on the statistical analysis and to Dr J Wright for revision of the english version of the manuscript.

\section{REFERENCES}

Abalos JW, Wygodzinsky P 1951. Las Triatominae argentinas (Reduviidae, Hemiptera). An Inst Med Reg Monogr 2.

Barth R 1956. Estudos anatomicos e histológicos sobre a subfamilia Triatominae (Hemiptera, Reduviidae). VI Parte: Estudo comparativo sobre a espermiocitogênese das espécies mais importantes. Mem Inst Oswaldo Cruz 54: 599-624.

Forattini OP 1980. Biogeografia, origem e distribuição da domiciliação de Triatomíneos no Brasil. Rev Saúde Públ S Paulo 14: 265-299.

García BA, Canale DM, Blanco A 1995. Genetic structure of four species of Triatoma (Hemiptera, Reduviidae) from Argentina. J Med Entomol 32: 134-137.

Gorla DE, Jurberg J, Catalá SS, Schofield CJ 1993. Sys- tematics of Triatoma sordida, T. guasayana and $T$. patagonica (Hemiptera, Reduviidae). Mem Inst Oswaldo Cruz 88: 379-385.

Hornos S, Cestau R, Canale D, Diotaiuti L, Perez R, Panzera F 1996. Cytogenetic studies of Triatoma guasayana, T. sordida and T. patagonica (HemipteraReduviidae). Mem Inst Oswaldo Cruz 91 (Suppl.): 123.

Panzera F, Alvarez F, Sanchez-Rufas J, Pérez R, Suja J, Scvortzoff E, Dujardin JP, Estramil E, Salvatella R 1992. C-heterochromatin polymorphism in holocentric chromosomes of Triatoma infestans (Hemiptera: Reduviidae). Genome 35: 1068-1074.

Panzera F, Pérez R, Panzera Y, Alvarez F, Scvortzoff E, Salvatella R 1995. Karyotype evolution in holocentric chromosomes of three related species of triatomines (Hemiptera-Reduviidae). Chrom Res 3: 143-150.

Panzera F, Pérez R, Hornos S, Panzera Y, Cestau R, Delgado V, Nicolini P 1996. Chromosome numbers in the Triatominae (Hemiptera- Reduviidae): A Review. Mem Inst Oswaldo Cruz 91: 515-518.

Rebagliati P, Mola L, Papeschi A, Wisnivesky-Colli C 1995. Similitud citogenética entre Triatoma sordida y T. guasayana. Abst. XXVI Congreso Argentino de Genética, I Jornadas Argentino-Chilenas de Genética, Argentina, p. 233.

Schofield CJ 1994. Triatominae. Biología y Control. Eurocommunica Publications, UK, $77 \mathrm{pp}$.

Schreiber G, Pellegrino J 1950. Eteropicnosi di autosomi come possibile meccanismo di speciazione. Sci Genet 3: 215-226.

Sokal RR, Rohlf FJ 1981. Biometry, 2nd ed., WH Freeman \& Company, New York, xviii-859 pp.

Usinger RL, Wygodzinsky P, Ryckman RE 1966. The biosystematics of Triatominae. Annu Rev Entomol 11: 309- 330.

Wisnivesky-Colli C, Gurtler RE, Solarz ND, Schweigmann NJ, Pietrokovsky SM, Alberti A, Flo J 1993. Dispersive flight and house invasion by Triatoma guasayana and T. sordida in Argentina. Mem Inst Oswaldo Cruz 88: 27-32.

Wisnivesky-Colli C, Schweigmann NJ, Pietrokovsky S, Bottazzi V, Rabinovich JE 1997. Spatial distribution of Triatoma guasayana (Hemiptera: Reduviidae) in Hardwood Forest Biotopes in Santiago del Estero, Argentina. J Med Entomol 34 (in press). 
Meiotic Studies in Triatoma sordida and T. guasayana • P Rebagliati et al. 